\title{
Impairment no Goodwill: uma Análise Baseada na Divulgação Contábil
}

\section{Resumo}

Este estudo objetivou verificar se as empresas brasileiras de capital aberto divulgaram informações sobre o teste de Impairment no goodwill, no período de 2009 a 2011. A elaboração de uma métrica com itens compulsórios de divulgação permitiu obter um índice de atendimento à norma e levantar quais informações as empresas têm divulgado. Os resultados indicam que em 2009 a maioria das empresas não evidenciou nenhuma informação exigida para o teste de Impairment no goodwill. No entanto, em 2010 e 2011, o percentual de empresas que nada evidenciaram sobre os procedimentos adotados para o teste decresceu. Aliado a isto, há indicativo de que o índice de evidenciação, em média, aumentou no decorrer do período analisado, porém mostra-se bastante heterogêneo. Informações sobre a taxa de desconto e a descrição da UGC não estiveram entre as informações mais evidenciadas. Os reflexos decorrentes de uma possível mudança na premissachave foi o item cuja divulgação foi a mais negligenciada pelas empresas em todos os anos. Como sugere a análise, esses resultados podem estar atrelados à adaptabilidade das empresas aos procedimentos de teste de Impairment, mas também podem decorrer das características de concentração de direitos de controle das empresas. Em linhas gerais, o aumento ao longo do período analisado no percentual de divulgação das premissas do teste de Impairment no goodwill não foi suficiente para reduzir as diferenças de divulgação apresentadas entre as empresas. Além disso, pôde-se perceber que muitas empresas não apresentaram consistência na divulgação dos itens da métrica de um ano para outro.

Palavras-chave: Evidenciação; Regulação; Impairment; Goodwill.

\section{Josilene da Silva Barbosa \\ Mestre em Contabilidade pela Universidade Federal do Paraná -UFPR. Contato: Prefeito Lothário Meissner, 632, Curitiba, PR, CEP.: 80210-070. E-mail: jslene@hotmail.com}

\section{Silvia Consoni}

Mestre em Contabilidade pela Universidade Federal do Paraná -UFPR. Contato: Prefeito Lothário Meissner, 632, Curitiba, PR, CEP.: 80210-070. E-mail: silviaconsoni@yahoo.com.br

\section{Luciano Marcio Scherer}

Professor da Universidade Federal do Paraná - UFPR e Doutor em Controladoria e Contabilidade pela Universidade de São Paulo - USP. Contato: Prefeito Lothário Meissner, 632, Curitiba, PR, CEP.: 80210070.

E-mail: Imscherer@ufpr.br

\section{Ademir Clemente}

Professor da Universidade Federal do Paraná - UFPR e Pós-doutorado pela Universidade Federal do Rio de Janeiro UFRJ. Contato: Prefeito Lothário Meissner, 632, Curitiba, PR, CEP.: 80210-070. E-mail: ademir@ufpr.br 


\section{Introdução}

No contexto de convergência às normas internacionais de contabilidade, entre as práticas implantadas a partir de 2008 no Brasil, destaca-se aquela que deriva do Pronunciamento Técnico CPC 15 - Combinação de Negócios. Este pronunciamento estabelece, entre outros, princípios e exigências específicas para a mensuração e reconhecimento do ágio por expectativa de rentabilidade futura (goodwill). Por sua vez, o CPC 04 - Ativo Intangível estabelece que o goodwill seja submetido ao teste de Recuperabilidade de Valor (teste de Impairment) de acordo com as disposições do CPC 01 - Redução no Valor Recuperável de Ativos.

A aprovação do Pronunciamento Técnico CPC 15 pela Comissão de Valores Mobiliários (CVM), em 2009, tornou-o de aplicação compulsória no âmbito das companhias de capital aberto. Consequentemente, tais companhias foram compelidas a realizar, nos termos da Deliberação CVM n. ${ }^{\circ}$ 580/09, posteriormente revisada pela Deliberação CVM n. ${ }^{\circ}$ 665/11, no mínimo anualmente, o teste de Impairment para verificar se o valor do goodwill pode ser recuperado no futuro. Desde então, não é mais permitida, a amortização contábil e sistemática desse ativo, a qual ficou restrita ao atendimento da legislação fiscal. Ainda, nos termos do CPC 01 (2010), a realização do teste de Impairment no goodwill implica a divulgação das informações relacionadas às premissas utilizadas no cálculo e aos fatores que ocasionaram a perda.

Para identificar se o goodwill perdeu a capacidade de gerar benefícios futuros, pode-se utilizar o valor em uso, que tem como base as estimativas de receitas e lucros futuros. Para Rield (2004) e Ramanna (2008), o teste de Impairment é guiado pela interpretação do ambiente econômico, por julgamentos e estimativas feitas pela administração. Por isso, os autores argumentam que a flexibilidade na definição das premissas de cálculo para o teste poderia levar as empresas a escolherem quando e por quanto reconhecerem perdas no goodwill.

Embora existam normas que dão diretrizes à divulgação, não há regras objetivas capazes de preencher todos os requisitos de uma boa divulgação. A escolha em relação ao "que", "como" e "quando" divulgar é um exercício de bom senso empresarial, ética e subjetividade (CVM, 2007). Portanto, se considerado que o teste de Impairment possui certo grau de subjetividade, os potenciais efeitos do reconhecimento de perdas e de suas implicações futuras devem estar disponíveis aos usuários da informação contábil para o adequado diagnóstico da posição financeira da empresa. Diante dos aspectos mencionados, questiona-se: Qual é o nível de evidenciação do teste de Impairment no goodwill pelas empresas brasileiras de capital aberto em relação às exigências do CPC 01 ?

O objetivo deste artigo é verificar se as empresas brasileiras de capital aberto divulgaram as informações exigidas pela norma contábil sobre a redução no valor recuperável no goodwill no período de 2009 a 2011. Daske, Hail, Leuz e Verdi (2013) afirmam que a qualidade da divulgação pode ser influenciada pelas práticas de Governança Corporativa e, portanto, a análise do presente estudo recai sobre a concentração dos direitos de controle e segmentos de listagem da BM\&FBovespa.

La Porta, Lopes-de-Silanes e Shleifer (1999) expõem que a retenção de informações por parte das empresas pode estar associada à estrutura de concentração de propriedade. Lopes e Alencar (2008) e Leuz (2006) complementam que empresas com controle disperso tendem a divulgar mais para reduzir a assimetria de informação. Em contraponto, empresas com controle mais concentrado divulgam menos, uma vez que seus investidores majoritários normalmente ocupam cargos importantes na empresa e, por isso, possuem acesso direto às informações. Andrade e Rossetti (2006) argumentam que a transparência e a divulgação de informações em obediência às leis estão relacionadas às melhores práticas de governança corporativa. Nesse sentido, têm-se as seguintes hipóteses teóricas: (1) empresas com controle disperso tendem a divulgar mais informações sobre a redução no valor recuperável do goodwill do que empresas com controle acionário concentrado; e (2) empresas listadas no segmento Novo Mercado da BM\&FBovespa tendem a divulgar mais informações sobre o teste de Impairment no goodwill do que as empresas listadas nos demais segmentos.

Diversos estudos foram realizados no Brasil sobre a divulgação da perda no valor recuperável no imobilizado e no intangível. Tais estudos constataram deficiências na divulgação do teste de Impairment e encontraram diferentes níveis de divulgação entre empresas que negociam ações na BM\&FBovespa, a exemplo de 
Silva, Marques e Santos (2009); Ono, Rodrigues e Niyama (2010); Souza, Borba e Zandonai (2011), Albani e Almeida (2012) e Machado, Cruz, Takamatsu e Lima (2013). Contudo, ao contrário do que ocorre no exterior, o enfoque empírico e restrito ao teste de Recuperabilidade no goodwill ainda não foi contemplado.

A mecânica para avaliação do valor recuperável, o período e a natureza da influência do goodwill na determinação do lucro das empresas difere substancialmente do conceito de amortização. A perda por impairment, diferentemente da amortização, indica que a baixa contábil do goodwill seria provocada apenas por questões relacionadas ao contexto operacional do investimento e, por isso, o reconhecimento da perda está condicionado a situações econômicas específicas e de estratégias de negócio das empresas. Somam-se a isto, particularidades para o reconhecimento do goodwill, bem como para a aplicação e divulgação do teste de Impairment em relação aos demais ativos.

Nesse contexto, surgem questões sobre o impacto que condições econômicas adversas poderiam provocar no futuro se levassem as empresas a registrarem baixas significativas desse ativo. Especialmente em períodos de crise, o impairment no goodwill pode causar um efeito de maior volatilidade nos resultados e na estrutura financeira das empresas. Além disso, escândalos corporativos, há mais de uma década, têm trazido à tona discussões sobre a divulgação de informações, se são verdadeiras e se deixam claro como os dados evoluem, resultando em regulações específicas. Assim, ao verificar se as empresas atendem aos requisitos compulsórios de divulgação do teste de Impairment no goodwill, busca-se contribuir para o entendimento do tratamento contábil dispensado a esse ativo pelas empresas no contexto brasileiro, especificamente, em relação à identificação e à evidenciação dos benefícios futuros subsequentes ao seu reconhecimento inicial.

\section{Referencial Teórico e Empírico}

\subsection{Normas de política contábil}

Em uma abrangente revisão de literatura, Healy e Palepu (2001) expõem que a divulgação de informações contribui para mitigar a assimetria de informação e problemas de agência. De acordo com Beyer, Cohen, Lys e Walther (2010), a demanda por informações surge porque o usuário interno normalmente tem mais informações sobre o desempenho econômico e financeiro da empresa do que o usuário externo e porque os provedores de capital, em função da separação entre propriedade e controle, não conseguem diretamente interferir na tomada de decisão dos gestores.

Evidências empíricas indicam que os benefícios da divulgação corporativa estão relacionados ao aumento de liquidez de mercado dos títulos das empresas (Welker, 1995; Leuz \& Verrecchia, 2000) e à redução ao custo de capital (Botosan, 2006; Lima, 2009; Lopes \& Alencar, 2010). No entanto, Shleifer e Vishny (1997) e La Porta et al. (1999) consideram que na perspectiva do conflito de interesse, acionistas majoritários abstêm-se do compromisso de divulgação, mesmo quando a divulgação aumenta o valor da empresa e reduz o custo de capital, pois seria o mesmo que abrir mão dos benefícios privados do controle.

A necessidade por informação no mercado de capitais nem sempre será atendida voluntariamente pelas empresas, pois os custos e benefícios da divulgação podem estar atrelados aos custos de agência, ao acesso às fontes de financiamento e aos custos de propriedade (Watts \& Zimmerman, 1986; Verrecchia, 2001). Healy e Palepu (2001) apontam que uma das razões para a regulação contábil são as imperfeições de mercado ou externalidades que limitam o trade-off dos custos e benefícios da divulgação voluntária. Talvez seja por isso, como assinala Beyer et al. (2010), que a literatura sobre regulação contábil tem dispensado esforços para identificar as razões pelas quais a regulação se justificaria sem, muitas vezes, conseguir descaracterizar os incentivos contratuais e de mercado que as empresas possuem para a divulgação voluntária.

Na interpretação de Verrecchia (2001) e de Dye (2001), não existe uma teoria abrangente da divulgação obrigatória. Leftwich (1980) aponta que se busca, muitas vezes, justificar a regulação contábil argumentando que seu objetivo é compensar a subprodução de informações, pois o uso de determinada 
informação por um indivíduo não impede o uso por outro (free rider). Outro argumento, ainda segundo Leftwich (1980), é que reguladores buscam proteger indivíduos que estão em desvantagem informacional. No entanto, Scott (2012) expõe que os interesses e a necessidade por informação divergem entre investidores e gestores, o que torna efetivamente difícil para o regulador calcular a distribuição de benefícios da produção de informações.

A fixação de políticas contábeis pelo regulador é tratada em termos de requisitos mínimos, como padrões geralmente aceitos de Contabilidade e de Auditoria, com o objetivo de reduzir divergências entre empresas em termos de divulgação, mensuração e método de apresentação (Bushee \& Leuz, 2005). Para Leuz e Verrecchia (2000), a divulgação compulsória força as empresas a se comprometerem no futuro, independentemente da situação dos negócios, com o provimento de informações aos participantes do mercado.

O International Accounting Standards Board (IASB) e o Financial Accounting Standards Board (FASB) têm adotado a posição de que, em uma economia de mercado, a consecução do objetivo da Contabilidade depende da divulgação de informações contábeis que permitam aos provedores de capital avaliar o potencial retorno das futuras oportunidades de investimento e monitorar o uso do capital comprometido (Ball, 2006; Scott, 2012). Consequentemente, normas e padrões são editados para modificar a quantidade e a qualidade das informações, principalmente, para atender aos interesses de investidores (Barth, Beaver \& Landsman, 2001).

Scott (2012) considera que normas de política contábil impedem as empresas de controlar a quantidade e o momento da divulgação de certas informações que produzem sobre si mesmas. Assim, os benefícios da regulação também estariam na credibilidade das informações disponibilizadas pelas empresas, pois é conferido aos órgãos reguladores, emissores de normas e auditores responsabilidade sobre a veracidade das informações. Porém, Welker (1995) expõe que, apesar das restrições para a elaboração, contabilização e evidenciação, as companhias ainda possuem certa discricionariedade na determinação do escopo, conteúdo, período e forma de evidenciar as informações aos usuários.

Para Daske, Hail, Leuz e Verdi (2013), aspectos econômicos e institucionais também podem limitar a efetividade de um conjunto de normas. Como a interpretação de normas é guiada pela subjetividade, os autores sugerem que a qualidade da divulgação é influenciada por práticas de monitoramento, instituições legais, governança corporativa e auditoria. Ball, Robin e Wu (2003) assinalam que, além dos mecanismos de enforcement, a estrutura de propriedade também pode direcionar as empresas a apresentar diferentes níveis de cumprimento à norma. Para La Porta et al. (1999), quanto mais concentrada a estrutura de propriedade, menores são os índices de divulgação de informações, pois a maioria dos investidores teria o poder de obter informações privilegiadas por outras fontes. Da mesma forma, Ball, Kothari e Robin (2000) consideram que, quando o controle é mais disperso, a divulgação é mais utilizada na redução da assimetria informacional e ela tende a ser mais tempestiva.

Particularmente, o processo de convergência às normas internacionais de contabilidade em vários países tem despertado o interesse sobre esses aspectos. Alguns pesquisadores têm discutido que a adoção de normas internacionais de contabilidade está sujeita às pressões políticas e não consegue representar, por si só, uma melhora na qualidade da divulgação (Ball, 2006; Ramanna, 2008). Por outro lado, existem evidências empíricas de que a adoção de normas internacionais de contabilidade é potencialmente útil, uma vez que as empresas em ambientes regulatórios relativamente fracos podem se beneficiar de menor custo de capital (Frost, Gordon \& Haves, 2006; Silva, 2013) e apresentar, em média, maior qualidade informacional dos lucros (Barth, Landsman, \& Lang, 2008).

No Brasil, o processo de convergência contábil às normas internacionais levou à criação do Comitê de Pronunciamentos Contábeis (CPC), em 2005, e à alteração da Lei das Sociedades Anônimas, em 2007. Contudo, a adoção integral das normas internacionais ocorreu apenas em 2010. Para Oliveira e Lemes (2011), a adoção inicial das normas internacionais no Brasil tenderia a aumentar o nível de divulgação das empresas, porém, outras pesquisas têm indicado deficiências no cumprimento de certos requisitos de divulgação obrigatória, como, por exemplo, na divulgação dos efeitos da primeira fase de convergência no resultado de 2008 (Santos, \& Calixto, 2010), critérios de reconhecimento, mensuração e evidenciação do 
ativo intangível (Avelino, Pinheiro, \& Lamounier, 2012; Moura, Dallabona, Fank, \& Varela, 2011) e reconhecimento da perda no valor recuperável do imobilizado e do intangível (Ono et al., 2010; Souza, 2011; Albano, \& Almeida, 2012; Machado et al., 2013).

\subsection{Redução ao valor recuperável do goodwill}

O ágio por expectativa de rentabilidade futura (goodwill) é o valor extra atribuído a uma empresa em virtude, por exemplo, de sua reputação, posição competitiva e lealdade dos clientes (Martins, Almeida, Martins \& Costa, 2010). O goodwill representa os "benefícios econômicos futuros resultantes dos ativos adquiridos, em uma operação de combinação de negócios, os quais não são individualmente identificados e separadamente reconhecidos" (CPC 15, 2011).

Martins, Diniz e Miranda (2012) esclarecem que o goodwill passa a existir "depois de todas as tentativas de mensuração objetiva de tudo o mais que está sendo adquirido. Diferentemente da prática contábil anterior em que, comumente, toda a diferença entre o valor pago e o valor contábil era classificada como esse tipo de ágio" (p. 307). Portanto, conceitualmente, o goodwill e o ágio por diferença de mercado dos ativos líquidos são acepções distintas. O goodwill é apurado pela diferença entre o valor de aquisição do investimento e o valor justo dos ativos líquidos da investida, sendo contabilizado pelo seu valor de custo líquido das perdas acumuladas por impairment. O ágio por diferença de valor de mercado dos ativos líquidos corresponde à diferença entre o valor justo e o valor contábil dos ativos líquidos da investida e é amortizado conforme a realização desses ativos.

A origem do goodwill está vinculada, portanto, aos ativos intangíveis não identificados separadamente e que representam, em parte, a expectativa de rentabilidade futura, mas também a alocação intencional e distorcida do valor da transação (Shalev, 2009). Certamente, as razões que norteiam o reconhecimento do goodwill podem ser variadas, como atuar em diferentes mercados e aumentar a participação naqueles em que já atua, ou tributárias, por exemplo.

Para verificar se as premissas utilizadas na identificação do goodwill permanecem estáveis e se as expectativas de rentabilidade futura serão concretizadas no período pós-aquisição, diferentemente do que ocorre com outros ativos, deve ser realizado o teste de Impairment, no mínimo, anualmente, independentemente de existirem indicações de perda. Qualquer perda por impairment no goodwill deve ser reconhecida no resultado do exercício e, ao contrário dos demais ativos, uma vez reconhecida, total ou parcialmente, não há possibilidade de reversão em período posterior (CPC 01, 2010). Portanto, o valor do impairment no goodwill não deve ser reconhecido contabilmente em conta retificadora, como ocorre com o valor do impairment no imobilizado.

No Brasil, antes da convergência às normas internacionais de contabilidade, o goodwill era amortizado em função do período esperado de uso de seu benefício econômico, que, na prática, sofreu influência fiscal. Em função da amortização, o ativo e o patrimônio líquido eram diminuídos ao longo do tempo, bem como o lucro líquido e o lucro por ação que absorviam o impacto em cada exercício social. Como não há mais um período específico para a realização de seus benefícios, coloca-se a necessidade do teste de Impairment.

Estudos que procuraram avaliar, em diferentes países, o impacto da transição às normas internacionais no resultado e no patrimônio líquido demonstraram que os ajustes decorrentes do tratamento do goodwill e do valor justo de ativos financeiros são os mais relevantes, afetando, significativamente, o resultado das empresas (Perramon \& Amat, 2006; Stenka, Ormrod \& Chan, 2008). A variação positiva nos lucros reportados por empresas no Reino Unido, como apresentado por Stenka et al. (2008), deve-se, principalmente, a não amortização do goodwill, a qual contribuiu para $24 \%$ de aumento total dos lucros, que cresceram em média $39 \%$ em função dos ajustes às normas.

Diferentemente dos resultados apresentados por Perramon e Amat (2006) e Stenka et al.(2008), Santos (2012) constatou que, em média, a exclusão dos custos de transação e prêmios na emissão de títulos e a inclusão dos incentivos fiscais no resultado foram os responsáveis pelo aumento no lucro reportado. 
Todavia, a interpretação de tais resultados implica considerar que no Brasil foram facultadas às empresas diversas opções de cumprimento das normas. Para exemplificar, desde 2008, foi prevista a realização do teste de Impairment no goodwill, porém, somente em 2009 a CVM, por meio da Deliberação n. ${ }^{\circ}$ 580/2009, exigiu tal procedimento. Portanto, essa questão ainda dificulta a avaliação no conjunto normativo do reflexo da amortização versus o teste de Impairment do goodwill.

O goodwill deve ser "testado para redução ao valor recuperável em nível que reflita a forma pela qual a entidade gerencia suas operações e com a qual o ágio estaria naturalmente associado" (CPC 01, 2010, item 82). Para tanto, esse ativo deve ser alocado a uma unidade geradora de caixa (UGC) ou grupos de UGCs. Entende-se que, havendo perda em uma UGC contendo goodwill, primeiramente ela deverá ser atribuída ao goodwill até o limite de seu valor. Se, ao zerar o valor do goodwill, ainda houver valor de perda para ser baixada, essa deverá ser distribuída, proporcionalmente, aos ativos componentes da respectiva UGC.

A identificação de UGCs, de acordo com Zucca e Campbell (1992) e Bini e Bella (2007), depende de exame e julgamento por parte da administração da empresa. Portanto, a maneira como são definidas é fundamental para a identificação de perdas no goodwill. Ainda, dependendo das premissas utilizadas, o teste de Impairment pode não reconhecer a existência de uma perda, ou então, só reconhecer perdas em situações econômicas específicas. Nesse sentido, Petersen e Plenborg (2010) investigaram, por meio de survey, o tratamento dispensado pelas empresas dinamarquesas à implementação do teste de Impairment no goodwill e constataram que os procedimentos para identificação de UGCs e de premissas do cálculo são negligenciados. Além disso, a taxa de desconto utilizada nas projeções de fluxos de caixa não é consistentemente estabelecida.

Como a alocação do goodwill a uma UGC e a identificação das premissas de cálculo pela administração são discricionárias, é necessário que seja realizada a divulgação de como e quando as perdas ocorrem. A divulgação, em termos de requisitos mínimos, é a última fase do processo de realização do teste de Impairment do goodwill (CPC 01, 2010, itens 126 - 135), independentemente de haver indicativos de perda ou de sua ocorrência (Figura 1).
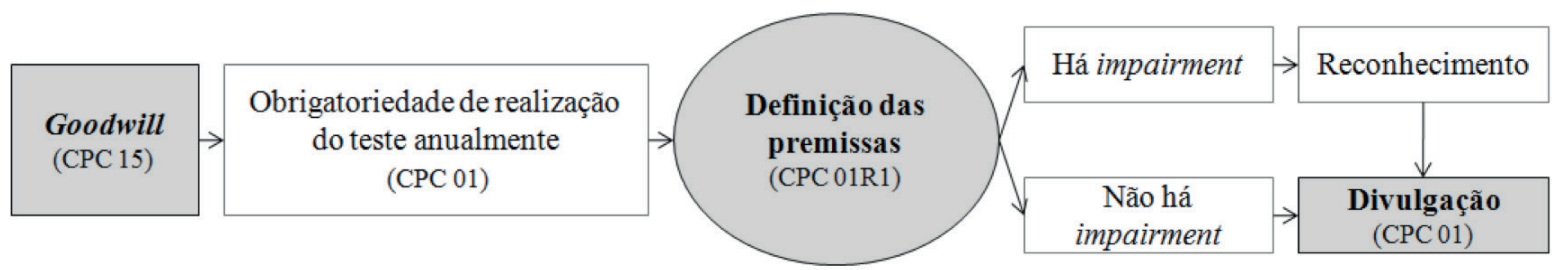

Figura 1. Fases do processo de teste de Impairment no goodwill

Embora as normas contábeis determinem que as empresas divulguem informações sobre premissas de cálculo, base utilizada e circunstâncias que ocasionaram a perda por impairment, pesquisas têm apontado que isso nem sempre ocorre (Li, Shroff, Venkataraman \& Zhang, 2011; Carlin, Finch, \& Ford, 2007; Bens, Heltzer, \& Segal, 2011). No Brasil, Souza (2011) constatou que as empresas que reconheceram perda por impairment em 2008 e 2009, inclusive no goodwill, não informaram, principalmente, a base utilizada no cálculo e a taxa de desconto. Além disso, a autora identificou que não houve mudanças significativas nos níveis de divulgação no exercício de 2009 em relação a 2008 e que empresas maiores auditadas por uma das Big Four e com menores índices de rentabilidade tendem a ter melhor nível de evidenciação.

Carvalho, Rodrigues e Ferreira (2010) observaram que em Portugal há uma heterogeneidade na forma como as empresas divulgam os requisitos acerca do reconhecimento e mensuração do goodwill, bem como do teste de Impairment. A informação é insuficientemente divulgada, principalmente acerca dos procedimentos e bases utilizadas na realização do teste. Esses autores ainda identificaram problemas de divulgação quanto aos ajustes decorrentes da convergência. As reconciliações nos resultados e no patrimônio líquido nem sempre são compreensíveis, o que afeta a comparabilidade e a relevância da informação divulgada entre as empresas. Essas questões resultam ainda mais acentuadas devido ao apego a conceitos e modelos de divulgação adotados anteriormente pelas empresas. 


\section{Procedimentos Metodológicos}

\subsection{Caracterização da amostra}

A amostra compreende as empresas brasileiras de capital aberto com ações negociadas na BM\&FBovespa e registro ativo no período de 2009 a 2011, definida conforme os critérios de seleção descritos na Tabela 1.

Tabela 1

\section{Seleção da amostra}

\begin{tabular}{lcc}
\hline Critérios & Número de empresas & $\%$ \\
\hline Empresas com registro ativo em 2011 & 360 & 100 \\
\hline Exclusões: & & \\
\hline Empresas sem demonstrações consolidadas & $(83)$ & 23 \\
\hline Empresas sem ativos intangíveis & $(15)$ & 4 \\
\hline Empresas não listadas em um dos anos & $(9)$ & 3 \\
\hline Empresas sem goodwill nos três anos & $(152)$ & 42 \\
\hline Empresas sem goodwill em um dos anos & $(15)$ & 4 \\
\hline Amostra final (2009-2011) & $\mathbf{8 6}$ & $\mathbf{2 4}$ \\
\hline
\end{tabular}

Para identificar as empresas com goodwill foram acessados o Balanço Patrimonial e a Nota Explicativa do grupo intangível. A escolha por analisar somente as empresas com registro ativo no triênio, embora introduza o viés de sobrevivência, deve-se à necessidade de adequar a amostra à proposta do estudo, a qual permeia o processo contínuo de adaptação das empresas à exigência de realização do teste de $I m$ pairment. Assim, a amostra final contempla 86 empresas.

\subsection{Instrumento utilizado na coleta dos dados}

Para verificar o nível de evidenciação do teste de Impairment no goodwill foi elaborada uma métrica com base nas exigências de divulgação do CPC 01 (2010). A métrica é composta por 13 itens, sendo os 3 primeiros relacionados apenas ao reconhecimento de perda. Os itens 4 a 13 referem-se à evidenciação dos procedimentos de realização do teste de Impairment no goodwill, o qual é obrigatório pelo menos anualmente (Figura 1).

\begin{tabular}{|c|c|}
\hline Item & Exigências \\
\hline 1 & Valor da perda para Unidade Geradora de Caixa (segmento, linha de produtos, etc.) \\
\hline 2 & Linha na DRE na qual a perda foi incluída \\
\hline 3 & Eventos ou circunstâncias que levaram ao reconhecimento da perda \\
\hline 4 & A base de cálculo, se valor em uso ou valor justo \\
\hline 5 & Descrição da Unidade Geradora de Caixa \\
\hline 6 & Informar o método utilizado no cálculo do valor recuperável \\
\hline 7 & A taxa de desconto utilizada na estimativa corrente \\
\hline 8 & Descrição das premissas-chave que serviram de base para o cálculo \\
\hline 9 & $\begin{array}{l}\text { Descrição da abordagem para determinar os valores alocados a cada premissa-chave (se refletem a experiência } \\
\text { passada ou se estão assentadas em informações externas) }\end{array}$ \\
\hline 10 & Especificar o período (em anos) sobre o qual a administração projetou o fluxo de caixa \\
\hline 11 & A taxa de crescimento utilizada para extrapolar as projeções de fluxo de caixa \\
\hline 12 & Os reflexos decorrentes de uma possível mudança na premissa-chave \\
\hline 13 & O valor contábil do goodwill alocado à Unidade Geradora de Caixa \\
\hline
\end{tabular}

Figura 1. Métrica para verificação das exigências de divulgação

Fonte: Pronunciamento Contábil CPC 01 (2010). 
Ressalta-se que o pronunciamento CPC 01 sofreu alterações em 2010 e passou a ser denominado CPC 01R1. Essa revisão, no que concerne à divulgação do teste de Impairment, exige informações sobre o valor da perda por segmento (se for o caso) e, ainda, o valor e as razões pelas quais a parcela do goo$d$ will permaneceu não alocada (se for o caso). Como as demais exigências de divulgação não foram substancialmente alteradas, optou-se por desconsiderar esses dois itens da métrica, tornando-a válida para a análise dos três anos. Essa decisão foi tomada após a análise das Notas Explicativas das empresas, pois foram percebidas inconsistências na forma como são reportadas as informações por segmento. Além disso, nenhuma empresa da amostra declarou não ter identificado o ágio decorrente de uma combinação de negócio ainda no período de reporte.

Também não foram consideradas as informações sobre: (a) os motivos para utilização de orçamentos e previsões como base para um período superior a cinco anos; (b) mudanças no conjunto de ativos da UCG desde a última estimativa; e (c) a taxa de desconto utilizada na estimativa anterior. Essas informações dependem da divulgação de outras, o que impossibilitaria o tratamento homogêneo das informações entre empresas da amostra, seja em função do recorte temporal de análise ou das particularidades de aplicação do teste adotadas por cada empresa.

Para verificar se houve realização do teste de Impairment no goodwill e, eventualmente, o reconhecimento de perda, foi lida na íntegra a Nota Explicativa do intangível. Para dirimir dúvidas, principalmente nos casos em que as informações apresentaram-se inconsistentes ou ausentes, usaram-se as seguintes palavras-chave: recuperável, Impairment; imparidade e ágio por expectativa de rentabilidade futura. Isso possibilitou obter informações em outras seções das Notas Explicativas. Para codificar a métrica, foi atribuído o valor igual a 1 (um) para cada item evidenciado e 0 (zero), caso contrário. Para obter o percentual de atendimento aos itens da métrica, foi dividida a soma dos pontos de cada empresa pelo total de itens.

Durante a coleta dos dados, constataram-se alguns equívocos de divulgação por parte das empresas. A empresa WLM divulgou o valor do goodwill no Balanço Patrimonial diferente do valor evidenciado em Notas Explicativas para os três anos da pesquisa. Problemas semelhantes foram constatados na evidenciação da empresa Camargo Correa em 2009, da Anhanguera em 2010 e da Suzano em 2011.

Finalizada a coleta, verificou-se que poucas empresas indicaram baixas por impairment no goodwill, sendo 2 empresas em 2009, 2 empresas em 2010 e 4 empresas em 2011. Nesse sentido, os itens 1 a 3 não são considerados na análise conjunta dos itens da métrica por referirem-se, especificamente, ao evento de reconhecimento da perda de um número relativamente pequeno de empresas. Dessas empresas, nenhuma indicou em 2009 e 2010 a linha da DRE na qual a perda foi incluída e, em 2010 e 2011, os eventos ou as circunstâncias que levaram ao reconhecimento da perda. Ressalta-se que a indicação das circunstâncias em que se deu a perda e da linha da DRE em que ela foi incluída possibilita ao usuário externo melhor compreender possíveis variações ocorridas em indicadores de análise de balanço e, consequentemente, garantem a comparabilidade das informações entre anos ou entre empresas.

Entre as empresas que reconheceram perda, a Gerdau (2009) e a Lupatech (2011) possuem o goo$d$ will com maior representatividade em relação ao intangível e ao ativo total. $\mathrm{Na}$ Gerdau, o goodwill representa $89,46 \%$ do intangível e $18,90 \%$ do ativo total. Na Lupatech, $95,18 \%$ do intangível e $32,80 \%$ do ativo total. As companhias Gafisa (2011) e Ideiasnet (2010) são as que reconheceram maior perda por impairment em relação ao goodwill no período, 5,70\% e 4,99\%, e, em relação ao intangível, 4,54\% e 3,84\%, respectivamente. Ambas as empresas apresentaram prejuízo nos anos em que divulgaram a perda, sendo que na Gafisa a perda provocou um aumento no prejuízo de 1,17\%, enquanto na Ideiasnet, de $11,33 \%$. As empresas Amil (40\%) e Ideiasnet (0\%) possuem o menor índice de evidenciação entre as empresas que reconheceram perda por impairment no goodwill, cujo percentual máximo foi de $100 \%$. As diferenças no percentual de atendimento à métrica de divulgação são exploradas na seção seguinte. 


\section{Apresentação e Análise dos Resultados}

Ao longo do período analisado, houve uma tendência das empresas em contemplarem um número maior itens de divulgação das informações sobre o teste de Impairment no goodwill, o que é mais perceptível se comparando 2009 e 2010 (Figura 2). Esse fato pode estar associado à adaptação das empresas em relação à identificação das premissas para o teste e de atendimento às exigências de divulgação. No entanto, essa expansão não alterou a "preferência" das empresas pela divulgação de determinados itens, embora o CPC 01 não atribua importância distinta a cada um dos itens que foram elencados na métrica.

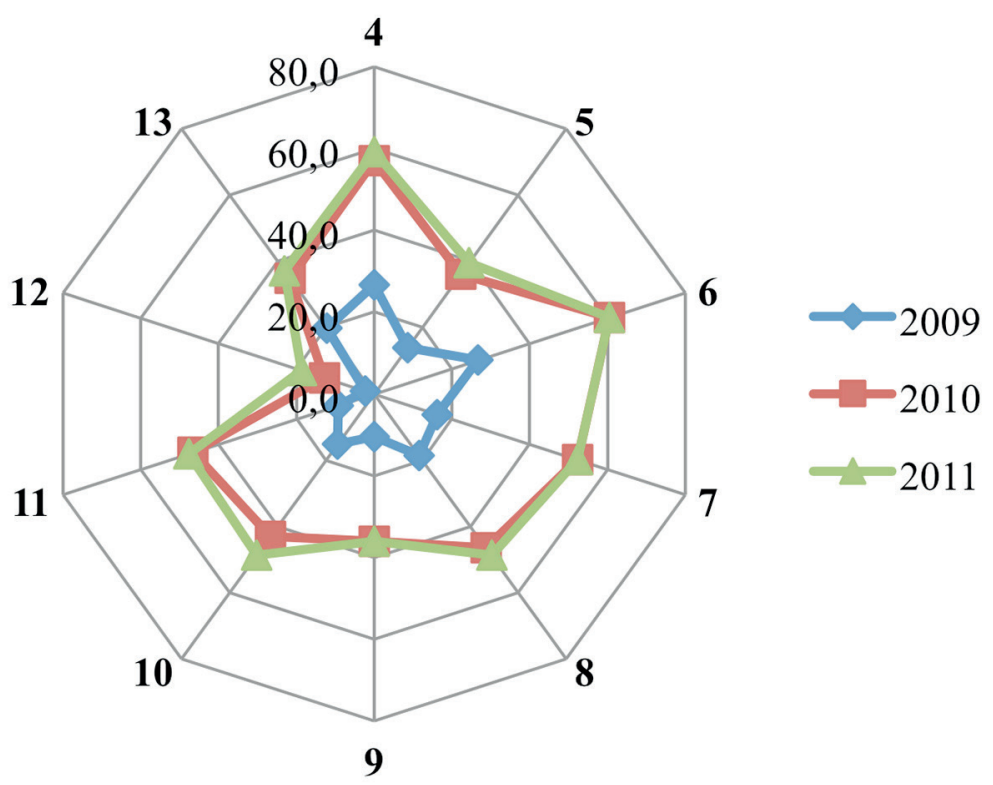

Figura 2. Percentual de divulgação dos itens 4 a 13 da métrica

Os reflexos decorrentes de uma possível mudança na premissa-chave (item 12) foi o item menos evidenciado no período, sendo 2,3\% em 2009, 12,8\% em 2010 e 18,6\% em 2011. Esse item também foi o que apresentou menor crescimento de 2009 a 2010. O método utilizado no cálculo do valor recuperável (item 6), a taxa de desconto utilizada na estimativa corrente (item 7) e a descrição da abordagem para determinar os valores alocados a cada premissa-chave (item 9) permaneceram com o mesmo percentual de evidenciação entre 2010 e 2011, 60,5\%, 52,3\% e 36,0\% respectivamente.

Todas as empresas da amostra que informaram o método utilizado no cálculo do valor recuperável (item 6) realizam o teste de Impairment com base no valor em uso, utilizando, para tanto, o fluxo de caixa descontado. Souza (2011), ao analisar o nível de evidenciação das empresas que reconheceram perda por impairment no imobilizado e no intangível, em 2008 e 2009, constatou que a base utilizada no cálculo da perda e a taxa de desconto foram os itens menos divulgados pelas empresas.

A taxa de desconto utilizada para a estimativa corrente (item 7) e o período em anos de projeção do fluxo de caixa (item 10) são parâmetros que influenciam no cálculo do valor da perda e, no entanto, apenas um pouco mais da metade das empresas da amostra os evidenciam. Entende-se que a divulgação dessas informações contribui para a análise do reflexo do montante das baixas por impairment ou da ausência de seu reconhecimento pelos usuários externos, bem como permite inferências a partir da análise comparativa entre empresas e setores. 
Tabela 2

Estatística descritiva dos percentuais de evidenciação

\begin{tabular}{lrcc} 
& $\mathbf{2 0 0 9}$ & $\mathbf{2 0 1 0}$ & $\mathbf{2 0 1 1}$ \\
\hline Média & 15,93 & 42,56 & 45,23 \\
\hline Mediana & 0,00 & 45,00 & 45,00 \\
\hline Desvio-Padrão & 26,50 & 34,95 & 35,60 \\
\hline Coeficiente de variação & 166,33 & 82,13 & 78,71 \\
\hline Mínimo & 0,00 & 0,00 & 0,00 \\
\hline Máximo & 100 & 100 & 100 \\
\hline Empresas & 86 & 86 & 86 \\
\hline
\end{tabular}

Os resultados apresentados na Tabela 2 indicam que, em média, o percentual de evidenciação efetuado pelas empresas variou positivamente de 2009 para 2011 (183,93\%). O desvio-padrão para os três anos indica que, em relação à média, o percentual de evidenciação é bastante disperso, pois algumas empresas nada divulgam enquanto outras evidenciam aspectos relacionados a todos os itens da métrica.

Adotando-se como parâmetro o coeficiente de variação, percebe-se que a divulgação se apresenta bastante heterogênea, em 2009, se comparado aos anos posteriores. Em 2009, 59,77\% das empresas da amostra não evidenciaram nenhuma das informações exigidas quanto ao teste de Impairment, mas 29,70\% e 25,58\% evidenciaram essa informação, em 2010 e em 2011, respectivamente. Além das empresas que não evidenciaram nenhuma informação exigida, há aquelas com percentuais baixos, como, por exemplo, $10 \%, 20 \%$ e 30\%. Em 2009, apenas 5 empresas apresentaram índice de divulgação com percentual entre $80 \%$ e 100\%, enquanto que, em 2010, são 19 e, em 2011, são 22 empresas. No entanto, apenas 3 empresas evidenciaram $100 \%$ dos itens da métrica ao longo do período.

Essas evidências condizem com os resultados encontrados em outros estudos, os quais apontam que, no Brasil, há deficiências no cumprimento de certos requisitos de divulgação obrigatória, como, por exemplo, de critérios de reconhecimento, mensuração e evidenciação do ativo intangível (Moura et al., 2011; Avelino et al., 2012) e do reconhecimento da perda no valor recuperável do imobilizado e do intangível (Ono et al., 2010; Souza, 2011). Entretanto, essa não é apenas uma característica encontrada no Brasil, pois, no contexto internacional, problemas na evidenciação do teste de Impairment no goodwill também foram documentados por Li et al. (2011), Carlin et al. (2007), Devalle e Rizzato (2012) e Carvalho et al. (2010).

Como o índice se mostrou bastante heterogêneo, verificou-se a adequação das empresas da amostra às exigências de evidenciação do teste de Impairment no goodwilll em relação à proporção desse ativo no grupo intangível (GI) e no ativo total (GA). Para tanto, os valores de cada uma dessas variáveis foram agrupados em quartis (Figura 3) como forma de realçar características das empresas da amostra. 


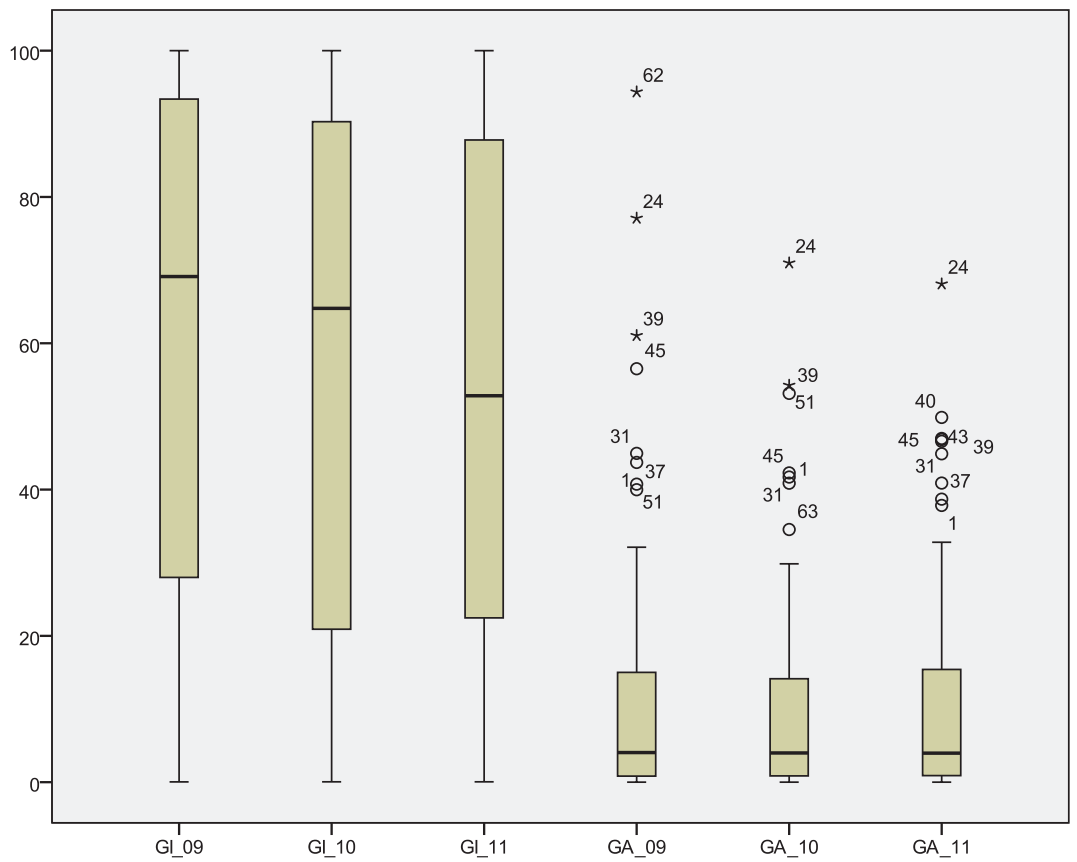

Figura 3. Proporção do goodwill no grupo intangível (GI) e no ativo total (GA)

Em 75\% das empresas, a variável GA assume proporção inferior a 16\% para ambos os anos. No entanto, nota-se que, em algumas empresas, a proporção do goodwill no ativo total é superior a $40 \%$ (valores extremos) e em $25 \%$ das empresas da amostra é pouco representativo, talvez devido às especificidades dos negócios. Em 2009, 75\% das observações da variável GI são menores que 93,62\% e, em 2011, 87,81\%. Percebe-se que em algumas empresas o goodwill representa o único ativo intangível registrado.

Para analisar o percentual de divulgação das empresas com maior e menor proporção do goodwill no grupo intangível e no ativo total, foram considerados apenas os dados do primeiro quartil (1Q) e os dados do quarto quartil (4Q).

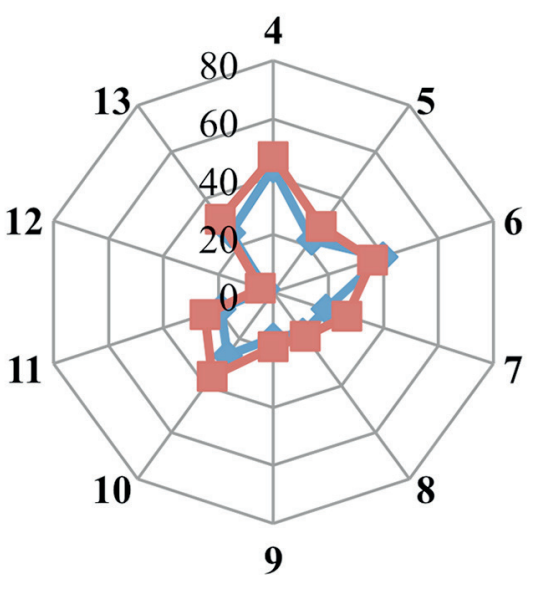

Figura 4. Percentual de divulgação das empresas do 1Q (2009-2011)

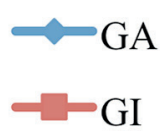

11

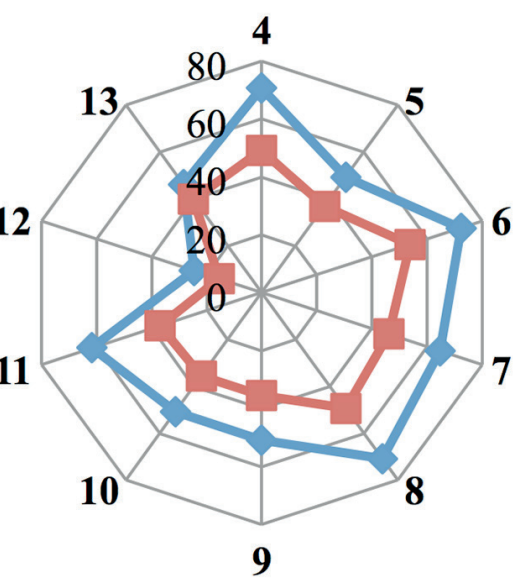

Figura 5. Percentual de divulgação das empresas do 4Q (2009-2011)

Nota-se que, em geral, quanto maior a representatividade do goodwill em relação ao ativo total (GA) e ao intangível (GI) maior tende a ser a divulgação. As empresas agrupadas no primeiro quartil do GI (Figura 4) divulgam mais do que as empresas agrupadas no primeiro quartil do GA (Figura 5). No entanto, há uma inversão no quarto quartil, onde as empresas do GA divulgam mais, sendo que a diferença entre os quartis é maior do que em relação ao primeiro caso. 
Esse ponto pode estar refletindo a discricionariedade da gestão das empresas na avaliação do custo/ benefício da divulgação dos requisitos de teste. Empresas com baixa representatividade do goodwill no ativo total podem não ter incentivos para divulgar se o eventual reconhecimento da perda não comprometer, significativamente, a condução dos negócios. As características do mercado em que tais empresas atuam e, consequentemente, a diversificação das atividades produtivas ou comerciais e fontes de financiamento também podem estar interferindo. Além disso, pode ser uma questão de governança corporativa, como sugerem Moura et al. (2011) ao investigarem aspectos de divulgação compulsória dos ativos intangíveis.

Depreende-se que, mesmo em situação de obrigatoriedade de divulgação, as empresas em geral tendem a reter informações. La Porta et al. (1999) argumentam que essa questão pode estar associada aos benefícios privados do controle. Os autores explicam que a concentração de controle é uma das adaptações criadas pelo mercado para compensar uma fraca estrutura de proteção ao investidor. Nesse sentido, a estrutura de concentração de propriedade indica o grau de diversificação dos acionistas e os potenciais problemas de agência entre acionistas majoritários e minoritários.

A criação de mecanismos internos e externos para assegurar que as decisões corporativas serão tomadas no melhor interesse dos investidores majoritário e minoritários compreendem aspectos da governança corporativa das empresas. Sob essa perspectiva, Andrade e Rossetti (2006) expõem que melhores práticas de governança corporativa levam as empresas a assumir um compromisso com a transparência e a obediência às leis e regulamentos (compliance). Nesse sentido, para explorar o comportamento apresentado pelas empresas da amostra em relação à divulgação do teste de Impairment e contribuir com a análise, consideraram-se aspectos como: (i) concentração dos direitos de controle e (ii) segmentos de listagem da BM\&FBovespa.

No Brasil, o controle acionário é predominantemente concentrado, contribuindo para o conflito de agência entre acionistas majoritários e minoritários (Silveira, Leal, Barros \& Carvalhal-da-Silva, 2009; Saito \& Silveira, 2010). Segundo Carvalhal-da-Silva (2004), o controle acionário é uma medida do poder de voto e, nesse sentido, a concentração de direitos de controle representa a percentagem de ações ordinárias detidas pelo acionista controlador. Para Siffert Filho (1998), a abertura econômica e as privatizações que ocorreram durante a década de 90 no Brasil implicaram mais mudanças na identidade dos controladores do que no grau de concentração acionária. Como aponta Carvalhal-da-Silva (2004), em média, o controle das empresas está em poder dos três maiores acionistas, sendo que $90,2 \%$ das empresas pesquisadas em 2002 possuíam um acionista majoritário, e apenas 9,8\% apresentavam estrutura de propriedade mais dispersa.

Nessa pesquisa, foram consideradas quatro categorias para análise da concentração do controle acionário, as quais foram adaptadas dos estudos de Pedersen e Thomsen (1997), Silveira et al. (2009) e Saito e Silveira (2010), conforme segue: (i) disperso - quando o maior acionista detém menos de 30\% do controle; (ii) dominante - quando o maior acionista detém entre 30\% e 50\% do controle; (iii) majoritário - quando o maior acionista detém mais de $50 \%$ do controle; e (iv) difuso - quando assim foi declarado pela empresa, ou seja, não havia acordo de acionistas e nem a identificação do controlador. As informações sobre controle acionário foram obtidas no formulário de referência das empresas disponível no site da CVM. Quando indicado que havia acordo de acionista, foi considerada a soma do percentual de ações ordinárias dos acionistas que faziam parte do acordo.

Observando-se o percentual de itens divulgados pelas empresas agrupadas de acordo com as características do controle acionário (Figuras 6 a 9), percebe-se que a maior diferença de adequação às exigências de evidenciação do teste de Impairment ocorre entre as empresas de controle disperso e majoritário, conforme o Gráfico 4 e o Gráfico 6. 


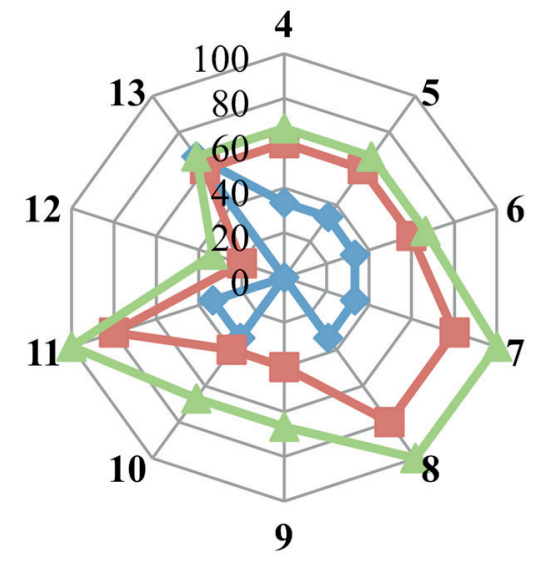

Figura 6. Percentual de divulgação versus controle acionário disperso

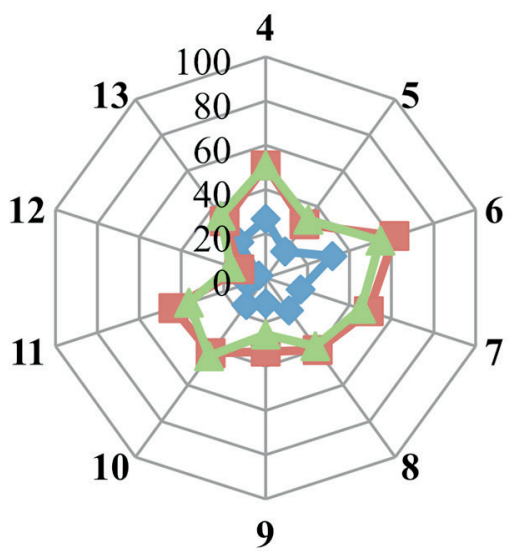

Figura 8. Percentual de divulgação versus controle acionário majoritário
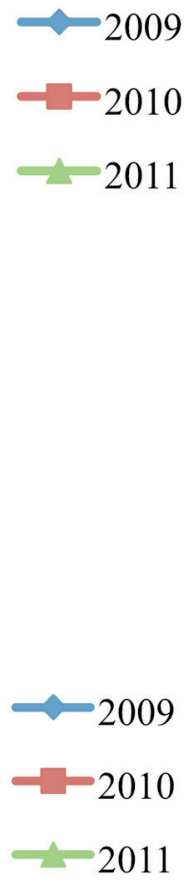

Nota-se que as empresas com controle disperso são as que mais divulgaram. A taxa de desconto, as premissas-chave e a taxa de crescimento (itens 7,8 e 1, respectivamente) foram evidenciadas por até $100 \%$ das empresas dessa categoria. Por outro lado, as empresas com controle majoritário são as que menos divulgam, sendo que apenas a base de cálculo (item 4) é divulgada por até $60 \%$ das empresas. O percentual de divulgação das empresas com controle difuso e dominante (Figuras 7 e 9) é semelhante, pois a maioria dos itens é divulgada por cerca de $60 \%$ das empresas.

No Gráfico 8, consideram-se esses aspectos ao longo do período de análise. Observa-se que, independentemente do ano e da concentração acionária, as empresas não têm divulgado os reflexos decorrentes de uma possível mudança na premissa-chave (item 12), o período (em anos) sobre o qual a administração projetou o fluxo de caixa (item 10) e a descrição da abordagem adotada para determinar os valores alocados a cada premissa-chave (item 9). 


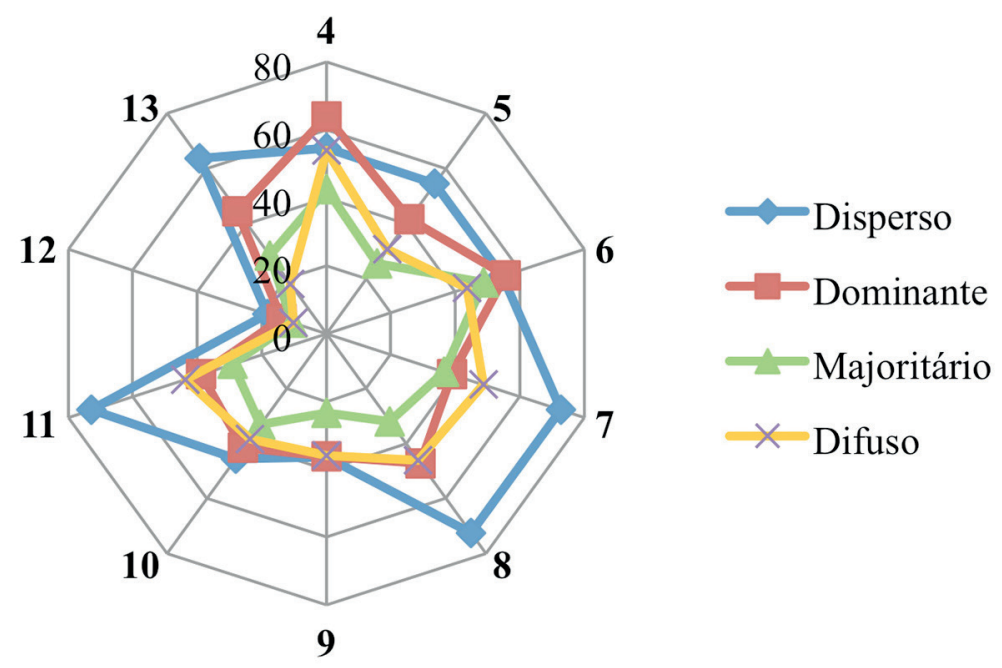

Figura 10. Percentual de divulgação versus características do controle acionário (2009-2011)

Os dados agrupados indicam, ainda, que as empresas têm apresentado comportamento similar entre os anos, ou seja, o aumento do percentual de itens evidenciados ao longo do tempo não alterou a percepção de que as empresas com controle mais disperso divulgam mais.

Essas evidências sugerem que o controle acionário tende a influenciar a divulgação das empresas. Como assinalam Lopes e Alencar (2008) e Leuz (2006), ao contrário do que ocorre em empresas com controle acionário concentrado, as empresas com controle disperso tendem a divulgar mais para reduzir a assimetria de informação. Empresas com controle mais concentrado buscam resolver problemas de assimetria via canais privados, pois investidores que detêm o controle fazem parte da gestão da empresa, do conselho de administração, o que favorece o acesso direto às informações.

Outro aspecto que pode interferir no processo de divulgação de informações pelas empresas é a adesão aos diferentes segmentos de listagem em bolsa. Em 2002, a BM\&FBovespa criou níveis diferenciados de governança corporativa, denominados de Nível I, Nível II e Novo Mercado, aos quais as empresas podem aderir voluntariamente. Para cada um dos Níveis e no Novo Mercado, são estabelecidas obrigações adicionais de divulgação de informações. As empresas do Nível II, além de aceitarem as obrigações contidas no Nível I, devem adotar um conjunto mais amplo de práticas de governança e de direitos adicionais para os acionistas minoritários. Para integrarem o Novo Mercado, além das exigências do Nível II, sujeitam-se a emissão de apenas ações ordinárias (BM\&FBOVESPA, 2013).

Classificando as empresas da amostra, segundo o segmento de listagem a que pertencem (Gráficos 11 a 14), observa-se que, no decorrer dos três anos, as empresas do Nível I ampliaram a divulgação de informações. Ressalta-se que, em 2009, foi o grupo de empresas que melhor se adaptou às exigências de divulgação do teste de Impairment no goodwill. O Nível II e o Novo Mercado, ao contrário do que se esperava, não são os segmentos de listagem que mais divulgam informações sobre o teste de Impairment no goodwill. Por outro lado, foram os segmentos que mantiveram a variação do percentual por item divulgado mais consistente e estável de 2010 a 2011, enquanto que, nos demais segmentos, alguns itens tiveram o percentual de divulgação diminuída. 


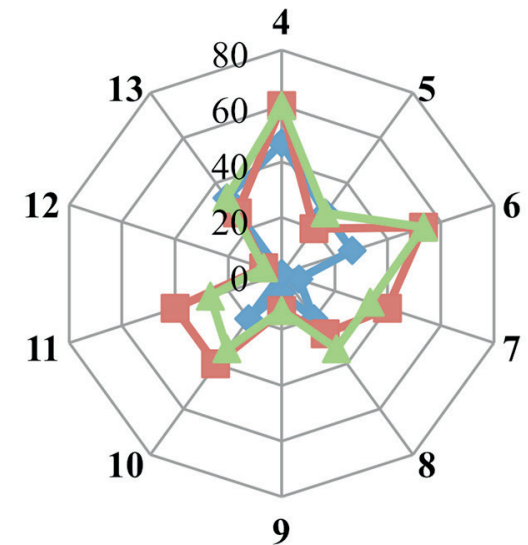

Figura 11. Percentual de divulgação no segmento Tradicional

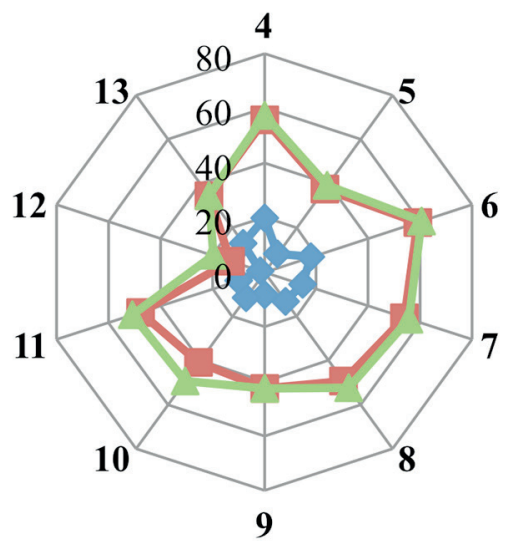

Figura 13. Percentual de divulgação no segmento Nível 2 e Novo Mercado

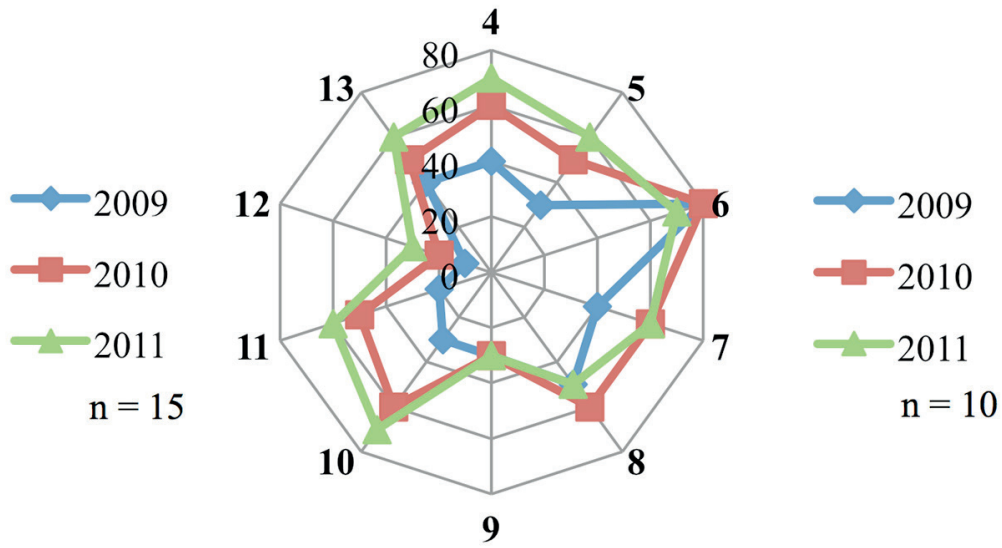

Figura 12. Percentual de divulgação no segmento Nível 1

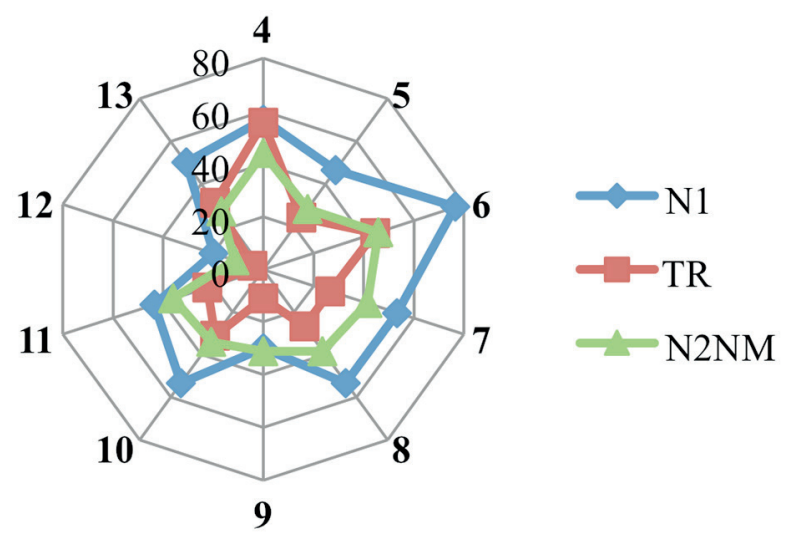

Figura 14. Percentual de divulgação por segmentos de listagem (2009-2011)

O Figura 14 agrupa o percentual de divulgação por item no período de análise. Nota-se que as empresas do Nível I possuem um percentual de divulgação por item superior ou igual aos demais segmentos. Em princípio, isso contraria a suposição de que as empresas do Nível II e Novo Mercado divulgam mais por se sujeitarem a melhores práticas de governança corporativa. Assinala-se, ainda, que o número de empresas da amostra no Nível 1 é 6 vezes menor do que o apresentado no Nível II e Novo Mercado. Nesse sentido, aspectos de benchmark e características intrínsecas do setor de atuação de cada companhia podem também ter contribuído para os resultados obtidos.

Buscou-se verificar se o percentual de divulgação das empresas do Nível II e do Novo Mercado estaria sendo influenciada pela representatividade do goodwill em relação ao ativo e ao intangível. No entanto, constatou-se que, em relação aos demais segmentos da análise, esse agrupou, em média, as empresas com maior proporção do goodwill no grupo intangível e no ativo total. Do mesmo modo, não há evidências explícitas de que a concentração do controle possa ter influenciado, pois não foi possível inferir que nesses segmentos predominam empresas com controle disperso.

Albani e Almeida (2012) ao avaliarem a divulgação do teste de Impairment no imobilizado e no intangível em empresas listadas no segmento Novo Mercado, no ano de 2010, concluíram que as empresas não têm apresentado informações de forma completa. Os autores identificaram, ainda, que $92,45 \%$ das empresas desse segmento eram auditadas pelas big four e sugerem que as características das empresas de auditoria não têm exercido substancial influência na divulgação do teste de Impairment. 
Da mesma forma, os resultados apresentados por Machado et al. (2013) indicam que empresas de um mesmo segmento de listagem apresentam níveis diferenciados de divulgação do teste de Impairment no imobilizado e no intangível. O estudo desses foi realizado em empresas listadas no Novo Mercado, sendo que as empresas que reconheceram perda ou reversões por impairment apresentaram melhores níveis de divulgação das premissas adotadas no teste em relação àquelas que não reconheceram perda. Ressalta-se, no entanto, que esse resultado deve ser tomado com cautela. Entende-se que as empresas devem estimar o valor do recuperável de ativos do imobilizado apenas se houver alguma indicação de desvalorização, ao contrário do que ocorre no intangível com vida útil indefinida ou de um ativo intangível ainda não disponível para uso, em que as empresas devem, independentemente de haver indícios de perda, estimá-la, no mínimo anualmente.

Em linhas gerais, a variabilidade do índice de evidenciação por empresa e entre os anos indica que atender à norma sobre o teste de Impairment pode ser uma questão de adaptabilidade, já que, em 2009, as empresas apresentam percentual de divulgação discrepante em relação aos demais anos. No entanto, em 2010 e 2011, há itens que são evidenciados por menos de 60\% das empresas. Além disso, a adequação das empresas para a divulgação do teste de Impairment do goodwill pode estar associada a aspectos de governança corporativa. Nesse sentido, foi possível verificar que o percentual de divulgação do teste de Impairment é maior em empresas com controle disperso. Ao ser comparado o percentual de divulgação das empresas do segmento de listagem Tradicional com as do Nível II e Novo Mercado, pode-se inferir que melhores práticas de governança contribuem para tornar a divulgação mais consistente. Por outro lado, as evidências apresentam-se um pouco distorcidas, comparando-se o percentual de divulgação das empresas do Nível 2 com os percentuais das empresas do Nível II e Novo Mercado.

\section{Considerações Finais}

O teste de Impairment no goodwill resulta de uma abordagem diferente na avaliação deste ativo para fins de apuração do balanço daquela adotada até 2009 pelas empresas brasileiras. Além disso, a adoção de uma abordagem de valor justo com base no valor em uso na determinação do valor recuperável não depende da existência de um mercado ativo. O Pronunciamento Técnico CPC 01 explicita que as estimativas do montante recuperável devem ser feitas em bases razoáveis que representem, fundamentalmente, os fundamentos econômicos dos negócios da companhia. Depreende-se, portanto, que todas as premissas utilizadas para o cálculo do valor recuperável deveriam ser divulgadas aos usuários da informação.

Nesse sentido, este artigo teve como objetivo verificar se as empresas brasileiras de capital aberto divulgaram as informações exigidas pela norma contábil sobre a redução no valor recuperável no goo$d w i l l$. Adicionalmente, consideraram-se, na análise, as seguintes hipóteses teóricas: (1) empresas com controle disperso tendem a divulgar mais informações sobre a redução no valor recuperável do goodwill do que empresas com controle acionário concentrado, e (2) empresas listadas no segmento Novo Mercado da BM\&FBovespa tendem a divulgar mais informações sobre o teste de Impairment no goodwill do que as empresas listadas nos demais segmentos. A elaboração de uma métrica com itens compulsórios de divulgação permitiu obter um índice de atendimento à norma, bem como levantar quais informações as empresas têm divulgado.

Há indícios de que, ao longo do tempo, as empresas têm aumentado o percentual de itens evidenciados, porém, isso não significa dizer que as empresas expandiram as informações em termos de conteúdo. Embora a análise não recaia sobre a qualidade das informações prestadas pelas empresas, pôde-se perceber que as informações sobre o teste de Impairment no goodwill apresentam-se, muitas vezes, incompletas e imprecisas, ou então, suprimidas de um ano para o outro. A análise dos resultados permite inferir que as empresas, em geral, negligenciam a divulgação de informações sobre o teste de Impairment no goodwill. Esse estudo está de acordo com Carvalho et al. (2010)no contexto português; Carlin et al. (2007) no con- 
texto australiano e Devalle e Rizzato (2012) no contexto europeu. Ainda em consonância com os estudos de Li et al. (2011), Bens et. al. (2011) e Souza (2011), foi possível identificar que as empresas apenas informam que realizaram o teste sem dar detalhes de como procederam, enquanto outras apenas expõem algumas das informações exigidas.

Quando a divulgação é imprecisa e inconsistente, o usuário externo pode ter prejudicada sua capacidade de tomar decisões, pois a utilidade das informações disponibilizadas é questionável. Especificamente, se ao teste de Impairment está implícito certo grau de subjetividade, os efeitos potenciais do reconhecimento de perdas por impairment no goodwill e de suas implicações futuras devem estar disponíveis aos usuários da informação contábil para o adequado diagnóstico da posição financeira da empresa. Esse aspecto leva a refletir se o preparador das demonstrações contábeis consegue avaliar a importância que cada exigência de divulgação representa para o usuário.

Em resposta às hipóteses teóricas do estudo, os resultados demonstram que empresas com controle disperso são as que mais divulgaram informações sobre o teste de Impairment no goodwill. Por outro lado, o Nível II e o Novo Mercado, ao contrário do que se esperava, não são os segmentos de listagem que mais divulgam informações sobre o teste de Impairment no goodwill. Dessa forma, observa-se que os resultados estão alinhados à hipótese 1 , porém não houve evidências que pudessem reafirma-lá, uma vez que, para a hipótese 2, os resultados não se apresentam consistentes.

Um papel potencial da divulgação obrigatória, como apresentado no Referencial Teórico, é servir como um dispositivo de compromisso e, consequentemente, levar as empresas a revelar informações tanto em momentos ruins como em momentos bons. No entanto, a efetividade da divulgação obrigatória pode ser bastante limitada sem mecanismos de enforcement adequados e adequada valorização das informações divulgadas pelos participantes do mercado. Como sugere Verrecchia (2001), os custos e benefícios da regulação não são óbvios, porque as empresas tendem a suportar os custos de retenção de informação, assim como têm incentivos privados para fornecer informações voluntariamente. Em síntese, os resultados desta pesquisa trazem à discussão um aspecto levantado por Bushee e Leuz (2005) de que as normas contábeis não têm conseguido reduzir divergências entre políticas contábeis das empresas.

Outra questão é se as empresas estão preparadas para atender às normas e se o regulador tem adotado uma postura que conduza à elaboração de normas claras e objetivas. Pode ser que as constatações deste estudo reflitam simplesmente a manifestação de uma falta de experiência acumulada com procedimentos de teste de Impairment pelas empresas e, que os casos observados de descumprimento das normas desaparecerão ao longo do tempo. No entanto, essa é uma questão que de fato a resposta só se tornará evidente no futuro. Os resultados obtidos e as inferências feitas servem como um lembrete de que, não obstante a existência de regras de informação complexas, estruturas de auditoria independente e o constante escrutínio dos mercados de capitais, as informações divulgadas apresentam-se inconsistentes.

Quanto às limitações da pesquisa, o alcance do objetivo deste estudo esteve condicionado aos pressupostos adotados na elaboração da métrica de evidenciação, pois não contempla critérios de verificação de qualidade da divulgação do teste de Impairment. Além disso, o que os pesquisadores entendem como cumprimento da norma pode ser diverso do entendimento de quem elabora as demonstrações contábeis e Notas Explicativas. Portanto, as conclusões obtidas ficam restritas aos itens que compõem a métrica e aos critérios que orientaram a coleta dos dados.

A pesquisa apresentou resultados que podem ser objeto de aprofundamento posterior, tanto teórico como empírico, como: (a) abordar especificamente o período de projeção, taxas de desconto e de crescimento para uma compreensão do grau de conservadorismo ou agressividade no desenvolvimento de estimativas do valor em uso pelas empresas, como no caso do teste de Impairment no goodwill; (b) explorar como os usuários das demonstrações contábeis leem, interpretam e utilizam as informações contábeis sobre o goodwill; (c) as razões que levam as empresas a oscilarem ou a não divulgarem informações que são estabelecidas em normas; e (d) consequências da intervenção da regulação na qualidade da informação divulgada e de sua relevância para o investidor. 


\section{Referências}

Albani, P. C. \& Almeida, J. E. F. (2012). Teste de impairment de ativos: análise comparativa da evidenciação das companhias abertas listadas no novo mercado por setor da economia e auditoria. Anais do Congresso USP de Iniciação Científica em Contabilidade, São Paulo-SP, Brasil, 9. Recuperado em 24 setembro, 2013, de http://www.congressousp.fipecafi.org/artigos122012/598.pdf.

Andrade, A. \& Rossetti, J. P. (2006). Governança Corporativa. 2 ed. São Paulo: Atlas.

Avelino, B. C., Pinheiro, L. E. T. \& Lamounier, W. M. (2012). Evidenciação de ativos intangíveis: estudo empírico em companhias abertas. Revista de Contabilidade e Organizações, 6(14), pp. 22-45.

Ball, R. (2006). International Financial Reporting Standards (IFRS): pros and cons for investors. Accounting \& Business Research, 36(Sup.1), pp. 5-27.

Ball, R., Kothari, S. P. \& Robin, A. (2000). The effect of institutional factors on properties of accounting earnings. Journal of Accounting and Economics. 29(1), pp. 1-51.

Ball, R., Robin, A. \& Wu, J. S. (2003). Incentives versus standards: properties of accounting income in four East Asian countries. Journal of Accounting and Economics. 36(1-3), pp. 235-270.

Barth, M. E., Beaver, W. H. \& Landsman, W. R. (2001). The relevance of value-relevance literature for financial accounting standard setting: another view. Journal of Accounting and Economics, 31(1-3), pp. 77-104.

Barth, M. E., Landsman, W. R. \& Land, M. H. (2008). International accounting standards and accounting quality. Journal of Accounting Research, 46(3), pp. 467-498.

BM\&FBOVESPA. (2013, junho). Governança corporativa. Recuperado 5 junho, 2013, de http://www. bmfbovespa.com.br/cias-listadas/consultas/governanca-corporativa/governanca-corporativa. aspx?idioma $=$ pt-br.

Beyer, A., Cohen, D. A., Lys, T. Z. \& Walther, B. R. (2010). The financial reporting environment: Review of the recent literature. Journal of Accounting and Economics, 50(2-3), pp. 296-343.

Bens, D. A., Heltzer, W. \& Segal, B. (2011). The information content of goodwill impairments and the adoption of SFAS 142. Journal of Accounting Auditing \& Finance, 26(3), pp. 527-557.

Bini, M. \& Bella, C. D. (2007). Determinants of market reactions to goodwill write-off after SFAS- 142. Managerial Finance, 33(11), pp. 904-914.

Botosan, C. A. (2006). Disclosure and the cost of capital: what do we know?. Accounting and Business Research, 36(Supl. 1), pp. 31-40. DOI: 10.1080/00014788.2006.9730042

Bushee, B. J. \& Leuz, C. (2005). Economic consequences of SEC disclosure regulation: evidence from the OTC bulletin board. Journal of Accounting and Economics, 39, pp. 233-264.

Carlin, T. M., Finch, N. \& Fprd, G. (2007). Goodwill impairment: an assessment of disclosure quality and compliance levels by large listed Australian firms. Recuperado em 5 janeiro, 2013, de http://dx.doi. org/10.2139/ssrn.963078.

Carvalho-Da-Silva, A. L. (2004). Governança corporativa, valor, alavancagem e política de dividendos das empresas brasileiras. Revista de Administração da USP, 39(4), pp.348-36.

CARVALHO, C., RODRIGUES, A. M., \& FERREIRA, C. (2010). Imparidade do goodwill na transição para a IFRS 3: o caso português. Estudos do ISCA, n.1.

Carvalho, C., Rodrigues, A. M. \& Ferreira, C. (2010). Imparidade do goodwill na transição para a IFRS 3: o caso português. Estudos do ISCA, (1) DOI: http://dx.doi.org/10.1234/ei.v0i1.568 
Comissão de Valores Mobiliários (CVM). (2007). Ofício-Circular/CVM/SNC/SEP n. 01/2007. Recuperado em 18 janeiro, 2013, de http://www.cvm.gov.br/port/atos/oficios/OFICIO-CIRCULAR-CVM-SNC-SEP-01_2007.asp.

(2009). Deliberação CVM n. 580, de 31 de julho de 2009. Recuperado em18 fevereiro, 2013, de http://www.cvm.gov.br/port/snc/deli580.pdf.

(2011). Deliberação CVM n. 665, de 04 de agosto de 2011. Recuperado em 18 fevereiro, 2013, de http://www.cvm.gov.br/port/infos/Comunicado_665_666_667.asp.

Comitê de Pronunciamentos Contábeis (CPC). (2010). Pronunciamento Técnico CPC 01 (R1): Redução ao valor recuperável de ativos. Recuperado em 20 janeiro, 2013, de www.cpc.org.br/.

. (2010). Pronunciamento Técnico CPC 04 (R1): Ativo intangível. Recuperado em 20 janeiro, 2013, de www.cpc.org.br/.

(2011). Pronunciamento Técnico CPC 15 (R1): Combinação de negócios. Recuperado em 20 janeiro, 2013, de www.cpc.org.br/.

Daske, H., Hail, L., Leuz, C. \& Verdi, R. (2013). Adopting a label: heterogeneity in the economic consequences of IFRS adoptions. Journal of Accounting Research, 51(3), pp. 495-547.

Devalle, A. \& Rizzato, F. (2012). The quality of mandatory disclosure: the impairment of goodwill. An empirical analysis of European listed companies. Procedia Economics and Finance, 2, pp. 101-108. doi: 10.1016/S2212-5671(12)00069-X

Dye, R. A. (2001). An evaluation of "essays on disclosure" and the disclosure literature in accounting. Journal of Accounting and Economics, 32, pp. 181-235.

Frost, C. A., Gordon, E. A. \& Hayes, A. F. (2006). Stock exchange disclosure and Market development: an analysis of 50 international exchanges. Journal of Accounting Research, 44(3), pp. 437-483. DOI: 10.1111/j.1475-679X.2006.00208.x

Healy, P. M. \& Palepu, K. G. (2001). Information asymmetry, corporate disclosure and capital markets: a review of empirical disclosure literature. Journal of Accounting and Economics, 31(1-3), pp. 405-440.

La Porta, R., Lopes-de-Silanes, F. \& Shleifer, A. (1999). Corporate ownership around the world. Journal of Finance, 54(2), pp. 471-517.

Leftwich, R. (1980). Market failure fallacies and accounting information. Journal of Accounting and Economics, 2(3), pp. 193-211.

Leuz, C. (2006). Cross listing, bonding and firms reporting incentives: a discussion of Lang, Raedy and Wilson. Journal of Accounting and Economics, 42(1-2), pp. 285-299.

Leuz, C. \& Verrecchia, R. E. (2000). The economic consequences of increased disclosure. Journal of Accounting Research. 38(Supl.), pp. 91-124.

Li, Z., Shroff, P. K., Venkataraman, R. \& Zhang, I. X. (2011). Causes and consequences of goodwill impairment loss. Review Accounting Studies, 16(4), pp. 745-778.

Lima, G. A. S. F. (2009). Nível de evidenciação x custo da dívida das empresas brasileiras. Revista Contabilidade \& Finanças, 20(49), pp. 95-108.

Lopes, A. \& Alencar, R. (2010). Disclosure and cost of equity capital in emerging markets: the Brazilian case. The International Journal of Accounting, 45(4), pp. 443-464.

Machado, E. A., Cruz, A. P C., Takamatsu, R. T. \& Lima, G. A. S. F. (2013). Evidências de disclosure de valor recuperável de ativos em firmas listadas no mercado acionário brasileiro. Revista Universo Contábil, 9(1), pp. 86-103. 
Martins, E., Almeida, D. L., Martins, E. A. \& Costa, P. S. (2010). Goodwill: uma análise dos conceitos utilizados em trabalhos científicos. Revista Contabilidade \& Finanças, 21(52), pp. 1-25.

Martins, E., Diniz, J. A. \& Miranda, G. J. (2012). Análise avançada das demonstrações contábeis: uma abordagem crítica. São Paulo: Atlas.

Moura, G. D., Dallabona , L. F., Fank, O. L. \& Varela, P. S. (2011). Boas Práticas de Governança Corporativa e Evidenciação Obrigatória dos Ativos Intangíveis. Anais do Congresso USP de Controladoria e Contabilidade, 11, São Paulo, SP, Brasil. Recuperado em 9 maio, 2013, de http://www.congressousp. fipecafi.org/artigos112011/507.pdf.

Oliveira, V. A. \& Lemes, S. (2011). Nível de convergência dos princípios contábeis brasileiros e norte-americanos às normas do IASB: uma contribuição para a adoção das IFRS por empresas brasileiras. Revista de Contabilidade Financeira, 22(56), pp. 155-173.

Ono, H. M., Rodrigues, J. M. \& Niyama, J. K. (2010). Disclosure sobre impairment: uma análise comparativa das companhias abertas brasileiras em 2008. Revista de Contabilidade do Mestrado em Ciências Contábeis da UERJ, Rio de Janeiro, 15(1), pp. 67-87.

Pedersen, T. \& Thomsen, S. (1997). European patterns of corporate ownership: a twelve-country study. Journal of International Business Studies, 28(4), pp.759-778.

Perramon, J. \& Amat, O. (2006). IFRS introduction and its effects on listed companies in Spain. Recuperado em 5 janeiro, 2013, de http://dx.doi.org/10.2139/ssrn.1002516.

Petersen, C. \& Plenborg, T. (2010). How do firms implement impairment tests of goodwill? ABACUS, 46(4), pp. 419-446.

Ramanna, K. (2008). The implications of unverifiable fair-value accounting: evidence from the political economy of goodwill accountings. Journal of Accounting and Economics, 45, pp. 253-281. doi:10.1016/j.jacceco.2007.11.006

Rield, E. J. (2004). An examination of long-lived asset impairments. The Accounting Review, 79(3), pp. 823-852.

Santos, E. S. (2012). Análise dos impactos dos CPCs da primeira fase de transição para o IFRS no Brasil: um exame dos ajustes aos resultados nas DFPs de 2008. Revista de Contabilidade e Organizações, 6(15), pp. 23-43.

Santos, E. S. \& Calixto, L. (2010). Impactos no início da harmonização contábil internacional (Lei 11.638/07) nos resultados das empresas abertas. Revista Administração de Empresas, 9(1).

Saito, R. \& Silveira, A. M. (2010). The importance of tag along rights and identity of controlling shareholders for the price spreads between dual-class shares: The Brazilian case. Brazilian Administration Review, 7(1), pp. 1-21.

Scott, W. R. (2012). Financial accounting theory. 6 ed. Toronto: Pearson.

Shleifer, A. \& Vishny, R. (1997). A survey of corporate governance. The Journal of Finance, 52(2), pp. 737-783.

Silva, P. D. A. S., Marques, J. A. V. C. \& Santos, O. M. (2009). Análise da evidenciação das informações sobre o impairment dos ativos de longa duração de empresas petrolíferas. Revista Base, 6(3), pp. 258-274.

SILVA, R. L. M. (2013). Adoção completa das IFRS no Brasil: qualidade das demonstrações contábeis e o custo de capital próprio. Tese de doutorado, Programa de Pós-Graduação em Controladoria e Contabilidade, Faculdade de Economia, Administração e Contabilidade da Universidade de São Paulo

Silveira, A. M., Leal, R. P. C., Barros, L. A. B. C. \& Carvalhal-da-Silva, A. L. (2009). Evolution and determinants of firm-level corporate governance quality in Brazil. Revista de Administração, 44(3), pp. 173-189.

Siffert Filho, N. F. (1998). Governança Corporativa: Padrões internacionais e evidências empíricas no Brasil nos anos 90. Revista do BNDES, 5(9), p. 1-22 
Shalev, R. (2009). The information content of business combination disclosure level. The Accounting Review, 84(1), pp. 239-270.

Souza, M. M. S (2011). Perda no valor recuperável de ativos: fatores explicativos do nível de evidenciação das empresas de capital aberto brasileiras. Dissertação de Mestrado, Universidade Federal de Santa Catarina, Florianópolis, SC, Brasil.

Souza, M. M. S., Borba, J. A. \& Zandonai, F. (2011). Evidenciação da perda no valor recuperável de ativos nas demonstrações contábeis: uma verificação nas empresas de capital aberto brasileiras. Revista Contabilidade Vista \& Revista, 22(2), pp.67-91.

Stenka, R. I., Ormrod, P. \& Chan, A. (2008). Accounting for business combinations: the consequences of IFRS adoption for UK listed companies. Recuperado em 05 janeiro, 2013, de http://dx.doi. org/10.2139/ssrn.1276826.

Verrecchia, R. E. (2001). Essays on disclosure. Journal of Accounting and Economics, 32(1-3), pp. 97-180.

Watts, R. L. \& Zimmerman, J. L. (1986). The Contracting Process. In Positive Accounting Theory. New Jersey: Prentice Hall.

Welker, M. (1995). Disclosure policy, information asymmetry, and liquidity in equity markets. Contemporary Accounting Research, 11(2), pp. 801-827.

Zucca, L. J. \& Campbell, D. R. (1992). A closer look at discretionary write downs of impairment assets. Accounting Horizons, 6(3), pp. 30-41. 